\title{
"The Relative Impact of Barriers to Care Among Military Health Services Personnel: Exploring Differences Using Context Specific Scenarios"
}

Jennifer Born ( $\boldsymbol{\nabla}$ jennifer.born@forces.gc.ca)

National Defence Headquarters

Christine Frank

National Defence Headquarters

Research Article

Keywords: Access to care, providers, military, mental health, physical health

Posted Date: June 1st, 2021

DOI: https://doi.org/10.21203/rs.3.rs-558730/v1

License: @ (1) This work is licensed under a Creative Commons Attribution 4.0 International License. Read Full License 


\section{Abstract}

Background: Military health care providers often under access both physical and mental health care, yet research has predominantly focused on barriers to mental health care. This study explored a comprehensive set of barriers using hypothetical scenarios to quantify barrier impact on access to both mental and physical health care.

Methods: Canadian military health services personnel $(\mathrm{N}=1033)$ completed one of two electronic surveys (assessing either physical health or other mental health barriers) that captured participant's demographics, health, endorsement of barriers, intent to seek care, and whether the respondent would access care in different health scenarios (pneumonia, back injury, depression and post-traumatic stress disorder). Logistic regression was used to calculate odds of not accessing care (versus accessing care) for each of the four health scenarios.

Results: All barrier factors independently predicted increased odds of not accessing care for all four scenarios. When entered into an adjusted model none of the barrier factors significantly predicted accessing care in the physical health scenarios. Staffing and workload resources and Intention to self-treat were significant predictors of accessing care in the mental health scenarios. Weak general intentions to access care was the strongest predictors of not accessing care across all four scenarios.

Conclusions: The impact of barriers on simulated accessing care behaviour differs depending on the context for which one is accessing care, with access to resources and intent to self-treat driving mental health care seeking. Intent appears to be the most impactful predictor of accessing care potentially mediating the effect of other barrier types on care seeking.

\section{Background}

Similar to their civilian counterparts, military health care providers (HCPs) work under physically and mentally demanding conditions (1) and are at increased risk of experiencing mental and physical health issues $(2,3)$. Additionally, military HCPs are exposed to unique stressors related to the military environment in which they operate $(4,5)$. Yet evidence suggests military personnel $(6)$ and civilian health care providers (7) do not access care when they should[1]. Not accessing care or delaying treatment can lead to worse health outcomes for the provider, but can also put their patients at risk $(8,9)$. This is especially concerning for military HCPs who are directly responsible for the health of military personnel, and indirectly responsible for the operational effectiveness of the entire organisation (10).

Often, failure to seek care is due to a denial of the need for treatment as well as, or in addition to, perceived barriers to care $(11,12)$. Thus, reducing or removing barriers should positively impact accessing care. However, it is essential to first identify and quantify existing barriers. Although there are many scales currently used to measure barriers to care in studies among military members (e.g., Hoge and colleagues (13)) and civilian providers (reviewed by Kay and colleagues (14)), there are several issues: 1) there is little consistency between these scales; 2) they tend to focus on stigma-related barriers; and 3) the development of items lacks an underlying theoretical base (15). In our preliminary research on barriers to care, we developed and validated a comprehensive measure of barriers using an existing theoretical framework that was created to explain behaviour and behaviour change (i.e., Michie et al., 2005 (16)) and focus group discussions with our target population (see Frank \& Born, 2021 (17) for details).

Aside from a recent publication by Britt and colleagues (18), most research on barriers to care in military populations have focused exclusively on barriers to mental health care. Additionally, numerous studies have quantified the prevalence of different types of barriers (i.e., whether that barrier exists) among both providers (19) and military personnel (20), but there is limited information, particularly for physical health, about the relative impact of those barriers (i.e., whether the barrier inhibits care seeking), and how best to mitigate the impact of those barriers in order to improve care. There is evidence to suggest that stigma is experienced in military populations (20) and that additional systemic barriers are experienced by providers (19), but few studies compare the relative contribution of different types of barriers. In one such study, Sudom et al., (21) reported that though stigma was associated with having a need for mental health care in military members, it had no association with care seeking-propensity; whereas structural barriers and negative attitudes toward care were more likely to affect care seeking.

Using a validated scale developed based on a theoretical domain framework, this study will explore the prevalence and relative impact of a comprehensive set of barriers on hypothetical physical and mental health care access among CAF Health Services personnel.

[1] In the Canadian Armed Forces (CAF), members access primary care through the military system - which is separate from the publically funded provincial health care systems. To consult a military health care provider, appointments can be made with the individuals' Care Delivery Unit or members can drop-in to a daily sick parade (similar to a walk-in clinic). 


\section{Methods}

\section{Study population}

Between May and July 2019, all CAF Health Services personnel $(N=3,448)$ were invited, via their work email, to complete a survey assessing barriers to care. Of the 3,448 eligible participants, 277 had invalid emails. Participants were excluded from the sample if they completed less than $50 \%$ of the items or if they were not employed in a health services role.

\section{Data collection}

Participants were invited to complete an online questionnaire that included items measuring barriers, personal characteristics, and access to care using vignettes. After consenting to the study, participants were randomly assigned to complete one of two versions of the survey: access to care for mental health issues or access to care for physical health issues (22). Prior to completing the barrier items, participants read a prompt that indicated that the barrier items either related to seeking care for physical health issues exclusively or mental health issues exclusively. Aside from this, the 52-barrier items were identical across the two surveys. Participants rated the extent to which the barrier item would prevent them from seeking care using a 6-point scale (1-Extremely Unlikely to 6- Extremely Likely).

All participants completed demographic, military characteristic, and health-related items across both versions of the survey. Intent to access care and self-rated health were survey specific (see below). Intent to access care was assessed through a single item: "When faced with a physical/menta/ health issue, I intend to access care" rated on a 7-point scale (1-Strongly Disagree to 7- Strongly Agree). Self-rated health was assessed using a single item: "In general, how would you rate your physical/menta/ health?", rated on a 5-point scale (1-Very Poor to 5- Excellent).

\section{Primary outcome}

In each version of the survey, participants were presented with two hypothetical scenarios: depression and post-traumatic stress disorder (PTSD) in the mental health survey; and pneumonia and back injury in the physical health survey. Each vignette was developed and vetted by the appropriate health professionals to ensure accurate progression of symptoms to the point where the individual should objectively seek formal care. Participants were asked to choose which action they would take in the presented scenario. The responses were dichotomized: not accessing care (i.e., choosing "I would do nothing/wait and see", "I would self-treat", or "I would informally consult a colleague or peer") was coded as one, while accessing care (i.e., choosing "I would seek formal treatment using CAF health services", or "I would seek formal treatment using civilian health services"), was coded as zero.

\section{Analysis}

The prevalence of each barrier type was calculated as the percentage of participants who positively endorsed at least one item within a factor. The choice was made to dichotomize barrier score due to a non-linear relationship between the factors and care-seeking. Barrier items were grouped into eight barrier factors as defined in previous research by Frank and Born (17). Table 1 provides a brief description of the factors and their psychometric properties. Barrier factors included: CAF HCP identity (e.g., If I accessed care, members of my unit might have less confidence in me as a health care provider), Discomfort accessing care at work (e.g., I'm uncomfortable receiving care from colleagues), Conflict with career goals (e.g., Accessing care would harm my career), Staffing and workload resources (e.g., My workload is too heavy for me to leave and access care), Knowledge and ability to access care (e.g., I don't know how to access the services available to me), Organizational and social support (e.g., My chain of command discourages the use of health services), Intentions to self-treat (e.g., I want to solve the problem on my own rather than access care), and Concerns about confidentiality (e.g., When I seek care, my medical file may be seen by those who shouldn't access it). Six barrier items that did not load onto factors were grouped into two additional categories: (1) Past experiences and expectations, and (2) Location related issues. These two additional factors were treated as individual characteristics in the analysis.

Table 1: Barriers items to care in each sample 


\begin{tabular}{|llllll|}
\hline & & $\begin{array}{l}\text { Physical Health Sample } \\
(\mathrm{n}=530)\end{array}$ & \multicolumn{2}{l|}{$\begin{array}{l}\text { Mental Health } \\
\text { Sample } \\
(\mathrm{n}=503)\end{array}$} \\
& & & & \\
& \# items & Factor Alpha & \% Missing & Factor Alpha & \% Missing \\
\hline Barrier Factors & & & & & \\
\hline CAF HCP identity & 11 & 0.96 & 0.2 & 0.97 & 0.6 \\
\hline Discomfort accessing care at work & 7 & 0.94 & 1.1 & 0.95 & 0.8 \\
\hline Conflict with career goals & 6 & 0.91 & 0.8 & 0.92 & 0.8 \\
\hline Staffing and workload resources & 5 & 0.89 & 0.2 & 0.90 & 0.4 \\
\hline Knowledge and ability to access care & 4 & 0.90 & 1.9 & 0.88 & 2.6 \\
\hline Organizational and social support & 4 & 0.91 & 3.2 & 0.86 & 3.0 \\
\hline Intention to self-treat & 5 & 0.85 & 0.4 & 0.86 & 1.6 \\
\hline Concerns about confidentiality & 4 & 0.90 & 0.4 & 0.89 & 1.0 \\
\hline Additional Barrier Categories & & & & & 2.0 \\
\hline Past experiences and expectations & 3 & 0.76 & 0.6 & 0.74 & 2.4 \\
\hline Location related issues & 3 & 0.71 & 1.3 & 0.74 & \\
\hline
\end{tabular}

Weak general intentions to access care was analyzed as a dichotomous variable with weak intentions (those reporting 1-Strongly Disagree to 5- Somewhat Agree) to the question "When faced with a physical/health issue, I intend to access care" coded as one and strong intentions (those reporting 6- Agree and 7-Strongly agree) coded as zero. Self-rated health was also dichotomized to quantify the proportion in poor health, with poor health coded as one (those reporting 1-Very Poor or 2- Poor) and good health (those reporting 3- Fair to 5- Excellent) coded as zero.

Initially, we used bivariate analysis to calculate the crude odds ratio (crude OR) for not accessing care in each scenario separately for each type of barrier and for all individual characteristics. Then, odds ratios (aORs) were adjusted by logistic regression for variables considered a priori as potential confounders. To account for missing data, the mi impute mvn command in Stata (23) with an iterative Markov Chain Monte Carlo (MCMC) method (24) was used to augment data (30 imputations). The estimates, standard errors and $95 \%$ confidence intervals, were calculated using the mi estimate command (25). Models were assessed using the largest fraction of missing information ( $F M l$; for number of imputations $\geq 100 \times \mathrm{FMI}$ ), average relative increases in variance (RVl; closer to zero the less effect missing data had on the variance estimate), and F-Tests $(p<0.05)$. All analyses were performed using Stata software (Version 14;(26)).

\section{Results}

Of the 3,171 CAF personnel who received an invitation to complete the survey, 1270 individuals responded; however, 221 respondents were excluded as they had completed less than $50 \%$ of the items, and an additional 16 participants were excluded as they were not employed in a health services role. This yielded a final sample of 1033 participants ( 503 from the mental health survey and 530 from the physical health survey) with a response rate of $32.6 \%$. See Table 2 for sample descriptions.

\section{Prevalence of barriers (Figure 1)}

Each barrier factor had a similar prevalence in both the mental health and physical health samples. The most endorsed barrier factors in both surveys were: Discomfort accessing care at work, Intentions to self-treat, Staffing and workload resources, and Conflict with career goals.

\section{Association between individual characteristics and not accessing care (Table 3)}

Compared to males, females had significantly higher crude odds of not accessing care for pneumonia. Those who prefer to access care in English had higher crude odds of not accessing care for back injury and depression compared to those who prefer to access care in French. Several associations were noted across military characteristics: the crude ORs were higher for those posted to rural locations, 
compared to those posted to urban areas for back injury; higher for junior officers, compared to junior non-commissioned members for pneumonia; and higher for those in specialty occupations, compared to core clinical trades for depression. Those with poor self-rated mental health had higher crude ORs in both mental health scenarios compared to those reporting better self-rated health. The crude ORs in the physical health scenarios did not differ significantly by self-rated physical health. Those reporting weak general intentions to access care had higher crude ORs across all scenarios. The two additional factors, associated with location related service issues, and experience and expectations about care, also produced significant estimates across all scenarios.

\section{Crude association between barriers and not accessing care (Figure 2)}

All eight barrier factors were significantly associated with not seeking care in all four scenarios. Specifically, endorsement of a barrier factor was associated with statistically higher crude odds of not accessing care, compared to those who did not endorse the barrier factor. Staffing and workload resources and Intentions to self-treat were the strongest predictors of not accessing care in the mental health scenarios. Staffing and workload resources and Conflict with career goals were the strongest predictors of not accessing care in the physical health scenarios. Discomfort accessing care at work, Concerns about confidentiality, and Knowledge and ability to access care were the weakest predictors. Crude OR estimates ranged from 1.87 to 2.91 for pneumonia, 2.24 to 4.53 for back injury, 2.48 to 4.03 for depression, and 2.74 to 4.71 for PTSD.

\section{Adjusted odds of not accessing care (Table 4)}

Holding all other variables constant, the odds of not accessing mental health care were significantly higher for those endorsing barriers related to resources $\left(\mathrm{aOR}_{\text {depression }}=2.64 ; \mathrm{aOR}_{\mathrm{PTSD}}=2.01\right)$ and Intentions to self-treat $\left(\mathrm{aOR}\right.$ depression $\left.=1.79 ; \mathrm{aOR} \mathrm{R}_{\mathrm{PTS}}=2.17\right)$. None of the eight barrier factors were significant predictors of accessing physical health care (at $p<0.05)$. Weak general intentions to access care was the only statistically significant predictor in the model across all scenarios $\left(\mathrm{aOR}_{\text {pneumonia }}=3.39 ; \mathrm{aOR}_{\text {back injury }}=3.28 ; \mathrm{aOR}\right.$ depression $=3.38$; $\left.\mathrm{aOR}_{\mathrm{PTSD}}=2.84\right)$. Age and rank were the only demographic and military characteristic predictors with statistically significant aORs, but these differences were only noted for not accessing care in the pneumonia scenario. Having accessed care in the past was significantly associated with not accessing care in the physical health scenarios $\left(\mathrm{aOR}_{\text {pneumonia }}=0.50 ; \mathrm{aOR}\right.$ back injury $\left.=0.47\right)$, but not in the mental health scenarios, where past care predicted increased likelihood of accessing care. Poor health predicted not accessing care in the depression scenario $\left(\mathrm{aOR}_{\text {depression }}=2.14\right)$, while the past experiences and expectations factor predicted not accessing care only in the pneumonia scenario $\left(\mathrm{aOR}_{\text {pneumonia }}=2.01\right)$.

Table 2: Demographics of physical health and mental health samples 


\begin{tabular}{|c|c|c|c|c|c|}
\hline & & \multicolumn{2}{|c|}{$\begin{array}{l}\text { Physical Health } \\
\text { Sample } \\
(n=530)\end{array}$} & \multicolumn{2}{|c|}{$\begin{array}{l}\text { Mental Health } \\
\text { Sample } \\
(n=503)\end{array}$} \\
\hline \multicolumn{2}{|l|}{ Variable } & Count & $\%$ & Count & $\%$ \\
\hline \multirow[t]{3}{*}{ Gender } & Female & 259 & 48.9 & 236 & 46.9 \\
\hline & Males & 242 & 45.7 & 234 & 46.5 \\
\hline & Not reported/Missing & 29 & 5.5 & 33 & 6.6 \\
\hline \multirow[t]{5}{*}{ Age Group } & 20 's & 90 & 17.0 & 82 & 16.3 \\
\hline & 30 's & 196 & 37.0 & 186 & 37.0 \\
\hline & 40 's & 163 & 30.8 & 131 & 26.0 \\
\hline & 50 's + & 59 & 11.1 & 77 & 15.3 \\
\hline & Missing & 22 & 4.2 & 27 & 5.4 \\
\hline \multirow[t]{3}{*}{ Preferred Language for Care } & English/No Preference & 436 & 82.3 & 412 & 81.9 \\
\hline & French & 75 & 14.2 & 64 & 12.7 \\
\hline & Missing & 19 & 3.6 & 27 & 5.4 \\
\hline \multirow[t]{4}{*}{ Rurality } & Urban & 291 & 54.9 & 228 & 45.3 \\
\hline & Peri-urban & 70 & 13.2 & 65 & 12.9 \\
\hline & Rural & 118 & 22.3 & 114 & 22.7 \\
\hline & Missing & 51 & 9.6 & 96 & 19.1 \\
\hline \multirow[t]{5}{*}{ Rank } & JNCM & 148 & 27.9 & 149 & 29.6 \\
\hline & SNCM & 88 & 16.6 & 81 & 16.1 \\
\hline & Jr.Officer & 175 & 33.0 & 146 & 29.0 \\
\hline & Sr. Officer & 96 & 18.1 & 93 & 18.5 \\
\hline & Missing & 23 & 4.3 & 34 & 6.8 \\
\hline \multirow[t]{4}{*}{ Years of service } & $<11$ years & 176 & 33.2 & 162 & 32.2 \\
\hline & 11 to 20 years & 204 & 38.5 & 201 & 40.0 \\
\hline & $>20$ years & 127 & 24.0 & 111 & 22.1 \\
\hline & Missing & 23 & 4.3 & 29 & 5.8 \\
\hline \multirow[t]{5}{*}{ Trade } & Clinical core & 300 & 56.6 & 255 & 50.7 \\
\hline & Clinical support & 100 & 18.9 & 91 & 18.1 \\
\hline & Specialty & 41 & 7.7 & 55 & 10.9 \\
\hline & Dental & 57 & 10.8 & 49 & 9.7 \\
\hline & Missing & 32 & 6.0 & 53 & 10.5 \\
\hline \multirow[t]{3}{*}{ Poor Self-rated MH } & Good & 502 & 94.7 & 431 & 85.7 \\
\hline & Poor & 28 & 5.3 & 72 & 14.3 \\
\hline & Missing & 0 & - & 0 & - \\
\hline \multirow[t]{2}{*}{ Access health care in the past } & No & 89 & 16.8 & 125 & 24.9 \\
\hline & Yes & 439 & 82.8 & 373 & 74.2 \\
\hline
\end{tabular}

Page 6/17 


\begin{tabular}{|clllll|} 
& Missing & 2 & 0.4 & 5 & 1.0 \\
General intention to access care & Weak & 303 & 57.2 & 296 & 41.2 \\
\cline { 2 - 6 } & Strong & 227 & 42.8 & 207 & 58.9 \\
\hline & Missing & 0 & - & 0 & - \\
\hline
\end{tabular}

JNCM- Junior non-commissioned member; SNCM- Senior non-commissioned member

Table 3: Crude odds ratios of not accessing care by individual characteristics. 


\begin{tabular}{|c|c|c|c|c|c|c|c|c|c|c|c|c|c|}
\hline \multicolumn{2}{|c|}{ Individual Characteristics } & \multicolumn{3}{|c|}{ Pneumonia } & \multicolumn{3}{|c|}{ Back Injury } & \multicolumn{4}{|c|}{ Depression } & \multicolumn{2}{|l|}{ PTSD } \\
\hline & & $\%$ & OR & $S E$ & $\%$ & OR & $S E$ & $\%$ & OR & $S E$ & $\%$ & OR & $S E$ \\
\hline & Overall & 25.3 & & & 18.0 & & & 46.7 & & & 28.7 & & \\
\hline \multirow[t]{2}{*}{ Gender } & Females & 29.5 & $\mathrm{R}$ & & 20.1 & $\mathrm{R}$ & & 45.3 & $\mathrm{R}$ & & 28.5 & $\mathrm{R}$ & \\
\hline & Male & 21.5 & $0.66^{\star}$ & 0.14 & 15.8 & 0.75 & 0.18 & 48.3 & 1.13 & 0.21 & 29.2 & 1.03 & 0.21 \\
\hline \multirow[t]{4}{*}{ Age Group } & 20's & 30.0 & $\mathrm{R}$ & & 16.9 & $\mathrm{R}$ & & 47.6 & $\mathrm{R}$ & & 30.5 & $\mathrm{R}$ & \\
\hline & 30 's & 26.2 & 0.83 & 0.23 & 16.8 & 1.00 & 0.34 & 49.5 & 1.08 & 0.29 & 30.7 & 1.01 & 0.29 \\
\hline & 40's & 23.9 & 0.73 & 0.22 & 22.1 & 1.40 & 0.48 & 48.9 & 1.05 & 0.30 & 28.5 & 0.91 & 0.28 \\
\hline & 50 's+ & 20.3 & 0.60 & 0.24 & 15.3 & 0.89 & 0.41 & 37.7 & 0.67 & 0.22 & 22.4 & 0.66 & 0.24 \\
\hline \multirow{2}{*}{$\begin{array}{l}\text { Preferred } \\
\text { Language } \\
\text { for Care }\end{array}$} & English & 26.6 & $\mathrm{R}$ & & 19.7 & $\mathrm{R}$ & & 49.8 & $\mathrm{R}$ & & 29.0 & $\mathrm{R}$ & \\
\hline & French & 18.9 & 0.64 & 0.20 & 9.5 & $0.43^{*}$ & 0.18 & 29.7 & $0.43^{\star *}$ & 0.12 & 26.6 & 0.88 & 0.27 \\
\hline \multirow[t]{3}{*}{ Rurality } & Urban & 25.9 & & & 14.1 & $\mathrm{R}$ & & 43.9 & $\mathrm{R}$ & & 28.3 & $\mathrm{R}$ & \\
\hline & $\begin{array}{l}\text { Peri- } \\
\text { urban }\end{array}$ & 25.7 & 0.99 & 0.30 & 15.7 & 1.13 & 0.42 & 47.7 & 1.17 & 0.33 & 32.3 & 1.21 & 0.37 \\
\hline & Rural & 22.9 & 0.85 & 0.22 & 23.7 & $1.89 *$ & 0.52 & 53.5 & 1.47 & 0.34 & 28.1 & 0.99 & 0.25 \\
\hline \multirow{2}{*}{$\begin{array}{l}\text { Location } \\
\text { related } \\
\text { issues }\end{array}$} & No & 21.7 & $\mathrm{R}$ & & 15.3 & $\mathrm{R}$ & & 41.8 & $\mathrm{R}$ & & 24.1 & $\mathrm{R}$ & \\
\hline & Yes & 39.8 & $2.38^{\star \star \star \star}$ & 0.56 & 29.8 & $2.35^{\star \star}$ & 0.60 & 67.7 & $2.92^{\star \star \star}$ & 0.70 & 47.4 & $2.83^{\star \star \star}$ & 0.67 \\
\hline \multirow[t]{4}{*}{ Rank } & JNCM & 19.6 & & & 19.7 & & & 45.0 & $\mathrm{R}$ & & 27.0 & $\mathrm{R}$ & \\
\hline & SNCM & 26.1 & 1.45 & 0.46 & 17.1 & 0.84 & 0.29 & 53.1 & 1.38 & 0.38 & 27.5 & 1.02 & 0.32 \\
\hline & $\begin{array}{l}\text { Jr. } \\
\text { Officer }\end{array}$ & 30.5 & $1.80 *$ & 0.48 & 17.7 & 0.88 & 0.25 & 46.6 & 1.07 & 0.25 & 30.1 & 1.16 & 0.30 \\
\hline & $\begin{array}{l}\text { Sr. } \\
\text { Officer }\end{array}$ & 22.9 & 1.22 & 0.39 & 17.7 & 0.88 & 0.30 & 45.2 & 1.01 & 0.27 & 29.0 & 1.10 & 0.32 \\
\hline \multirow{3}{*}{$\begin{array}{l}\text { Years of } \\
\text { service }\end{array}$} & $<11 \mathrm{yrs}$ & 25.7 & & & 16.0 & & & 42.6 & $\mathrm{R}$ & & 23.5 & $\mathrm{R}$ & \\
\hline & $\begin{array}{l}11 \text { to } 20 \\
\text { yrs }\end{array}$ & 25.5 & 0.99 & 0.23 & 17.7 & 1.13 & 0.31 & 50.8 & 1.39 & 0.30 & 30.7 & 1.44 & 0.35 \\
\hline & $>20 y r s$ & 23.6 & 0.89 & 0.24 & 21.3 & 1.42 & 0.42 & 45.1 & 1.10 & 0.27 & 31.5 & 1.50 & 0.41 \\
\hline \multirow[t]{4}{*}{ Trade } & Core & 24.8 & & & 20.0 & & & 43.9 & $\mathrm{R}$ & & 29.5 & $\mathrm{R}$ & \\
\hline & Support & 29.0 & 1.24 & 0.32 & 17.2 & 0.83 & 0.25 & 48.4 & 1.20 & 0.29 & 29.7 & 1.01 & 0.27 \\
\hline & Specialty & 17.1 & 0.63 & 0.27 & 9.8 & 0.43 & 0.24 & 60.0 & $1.92^{\star}$ & 0.58 & 31.5 & 1.10 & 0.35 \\
\hline & Dental & 26.3 & 1.09 & 0.36 & 17.5 & 0.85 & 0.32 & 40.8 & 0.88 & 0.28 & 18.4 & 0.54 & 0.21 \\
\hline $\begin{array}{l}\text { Past } \\
\text { diagnosis }\end{array}$ & No & 24.8 & $\mathrm{R}$ & & 18.1 & $\mathrm{R}$ & & 45.2 & $\mathrm{R}$ & & 27.3 & $\mathrm{R}$ & \\
\hline
\end{tabular}




\begin{tabular}{|c|c|c|c|c|c|c|c|c|c|c|c|c|c|}
\hline & Yes & 26.4 & 1.09 & 0.29 & 17.6 & 0.97 & 0.29 & 53.3 & 1.38 & 0.32 & 36.3 & 1.51 & 0.37 \\
\hline \multirow{2}{*}{$\begin{array}{l}\text { Poor Self- } \\
\text { rated health }\end{array}$} & No & 25.6 & $\mathrm{R}$ & & 17.2 & $\mathrm{R}$ & & 42.5 & $\mathrm{R}$ & & 24.7 & $\mathrm{R}$ & \\
\hline & Yes & 21.4 & 0.79 & 0.37 & 32.1 & 2.29 & 0.96 & 72.2 & 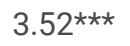 & 0.99 & 52.8 & $3.41^{\star * *}$ & 0.89 \\
\hline \multirow{2}{*}{$\begin{array}{l}\text { Access } \\
\text { health care } \\
\text { in the past }\end{array}$} & No & 38.2 & $\mathrm{R}$ & & 28.1 & $\mathrm{R}$ & & 49.6 & $\mathrm{R}$ & & 28.2 & $\mathrm{R}$ & \\
\hline & Yes & 22.8 & 0.48 ** & 0.12 & 16.0 & $0.49 * \star$ & 0.13 & 45.6 & 0.85 & 0.18 & 28.8 & 1.03 & 0.24 \\
\hline \multirow{2}{*}{$\begin{array}{l}\text { General } \\
\text { intention to } \\
\text { access care }\end{array}$} & Strong & 13.9 & $\mathrm{R}$ & & 8.3 & $\mathrm{R}$ & & 25.6 & $\mathrm{R}$ & & 13.5 & $\mathrm{R}$ & \\
\hline & Weak & 40.7 & $4.31^{\star \star \star}$ & 0.92 & 31.0 & $5.06 * \star \star$ & 1.28 & 61.5 & $4.63^{\star \star \star}$ & 0.92 & 39.5 & 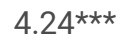 & 1.00 \\
\hline \multirow{2}{*}{$\begin{array}{l}\text { Past } \\
\text { experiences } \\
\text { and } \\
\text { expectations }\end{array}$} & No & 19.2 & $\mathrm{R}$ & & 12.4 & $\mathrm{R}$ & & 37.3 & $\mathrm{R}$ & & 20.1 & $\mathrm{R}$ & \\
\hline & Yes & 42.1 & $3.06^{\star * *}$ & 0.65 & 32.2 & $3.36 * \star \star$ & 0.76 & 69.8 & $3.88^{* \star *}$ & 0.83 & 50.7 & 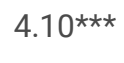 & 0.89 \\
\hline
\end{tabular}

\% in category who did not access care in given scenario; SE- standard error; JNCM- Junior non-commissioned member; SNCM- Senior noncommissioned member

${ }^{* * *} p<0.001,{ }^{* *} p<0.01,{ }^{*} p<0.05$

Table 4: Imputed logistic regression modelling: Adjusted odds ratios of not accessing care across all behavior scenarios. 


\begin{tabular}{|c|c|c|c|c|c|c|c|c|}
\hline \multirow[t]{2}{*}{ Model Variables } & \multicolumn{2}{|c|}{ Pneumonia } & \multicolumn{2}{|c|}{ Back Injury } & \multicolumn{2}{|c|}{ Depression } & \multicolumn{2}{|l|}{ PTSD } \\
\hline & $\mathrm{aOR}$ & $S E$ & $\mathrm{aOR}$ & $S E$ & $\mathrm{aOR}$ & $S E$ & $\mathrm{aOR}$ & $S E$ \\
\hline \multicolumn{9}{|l|}{ Individual characteristics } \\
\hline Female gender & 1.49 & 0.36 & 1.40 & 0.38 & 0.77 & 0.18 & 0.80 & 0.20 \\
\hline Age & $0.73^{*}$ & 0.11 & 1.19 & 0.19 & 0.93 & 0.12 & 0.87 & 0.12 \\
\hline Prefer accessing care in English & 1.03 & 0.37 & 1.09 & 0.48 & 1.82 & 0.66 & 0.86 & 0.32 \\
\hline JNCM & $0.37 \star \star$ & 0.11 & 0.83 & 0.27 & 0.76 & 0.21 & 0.75 & 0.22 \\
\hline Core trade & 0.84 & 0.21 & 1.07 & 0.30 & $0.62+$ & 0.15 & 0.95 & 0.24 \\
\hline Stationed in rural location & 0.71 & 0.21 & 1.55 & 0.49 & 1.52 & 0.42 & 0.86 & 0.25 \\
\hline Location related issues & 1.30 & 0.37 & 1.14 & 0.35 & 1.39 & 0.43 & 1.10 & 0.33 \\
\hline Poor self-reported health & 0.65 & 0.35 & 1.70 & 0.84 & $2.14^{\star}$ & 0.75 & 1.47 & 0.48 \\
\hline Accessed care in the past & $0.50 *$ & 0.14 & $0.47 *$ & 0.15 & 0.74 & 0.19 & 0.83 & 0.23 \\
\hline Weak general intentions & $3.39 * * \star$ & 0.82 & $3.28 * \star \star$ & 0.91 & $3.38^{\star \star \star}$ & 0.78 & $2.84^{\star \star \star}$ & 0.75 \\
\hline Past experiences and expectations & $2.01 *$ & 0.63 & 1.44 & 0.47 & 1.60 & 0.48 & 1.52 & 0.45 \\
\hline \multicolumn{9}{|l|}{ Barrier Factors } \\
\hline CAF HCP identity & 0.66 & 0.22 & 1.03 & 0.35 & 0.84 & 0.26 & 1.34 & 0.43 \\
\hline Discomfort accessing care at work & 0.79 & 0.25 & 0.80 & 0.29 & 0.77 & 0.22 & 0.85 & 0.26 \\
\hline Conflict with career goals & 1.44 & 0.40 & 1.67 & 0.53 & $1.65+$ & 0.45 & 1.23 & 0.36 \\
\hline Staffing and workload resources & 1.62 & 0.48 & $1.93+$ & 0.67 & $2.64^{\star \star \star}$ & 0.65 & $2.01 * \star$ & 0.54 \\
\hline Knowledge and abilities & 1.28 & 0.41 & 0.93 & 0.32 & 0.92 & 0.30 & 0.96 & 0.29 \\
\hline Organizational and social support & 1.22 & 0.48 & 0.95 & 0.38 & 0.88 & 0.32 & 1.43 & 0.48 \\
\hline Intentions to self-treat & 1.24 & 0.34 & 1.31 & 0.41 & $1.79 *$ & 0.44 & $2.17 * \star$ & 0.59 \\
\hline Concerns about confidentiality & 1.05 & 0.33 & 1.10 & 0.37 & 1.15 & 0.35 & 1.13 & 0.35 \\
\hline Model constant & 0.57 & 0.39 & $0.03^{* \star *}$ & 0.02 & $0.18^{*}$ & 0.12 & $0.14^{\star *}$ & 0.10 \\
\hline \multicolumn{9}{|l|}{ Model Descriptors } \\
\hline $\mathrm{n}$ & 530 & & 530 & & 503 & & 503 & \\
\hline Average $\left.\mathrm{RV}\right|^{\mathrm{a}}$ & 0.0228 & & 0.0278 & & 0.0394 & & 0.0320 & \\
\hline Largest FMI ${ }^{\mathrm{b}}$ & 0.1044 & & 0.1768 & & 0.1933 & & 0.1696 & \\
\hline \multirow[t]{2}{*}{ Model F Test } & \multirow{2}{*}{\multicolumn{2}{|c|}{$F(19,999077.7)=4.16$}} & \multicolumn{2}{|c|}{$F(19,674789.5)$} & \multicolumn{2}{|c|}{$F(19,344713.2)$} & \multicolumn{2}{|c|}{$F(19,515145.5)$} \\
\hline & & & $=3.34$ & & $=5.41$ & & $=4.45$ & \\
\hline$p$ & $<0.0001$ & & $<0.0001$ & & $<0.0001$ & & $<0.0001$ & \\
\hline
\end{tabular}

${ }^{\mathrm{a}} \underline{M} \geq 100 \times \mathrm{FMl}$, in all models where $\underline{M}$ (number of imputations) is sufficient; ${ }^{\mathrm{b}}$ The closer the RVI is to zero, the less effect missing data have on the variance estimate, in this case all RVI are low; JNCM- Junior non-commissioned member; ${ }^{* *} p<0.001,{ }^{* *} p<0.01,{ }^{*} p<0.05, \dagger p$ $\leq 0.06$

\section{Discussion}

The goal of this paper was to examine the prevalence and relative impact of a wide array of barriers on care seeking for both mental and physical health care. Examination of the endorsement of barrier factors revealed that Discomfort accessing care at work, Intentions to selftreat, Staffing and workload resources, and Conflict with career goals were all endorsed by approximately half of respondents across both 
the mental health and physical health surveys. Although there were some differences between the degree of endorsement of the factors across health condition, the estimates generally overlapped. This finding reproduced the conclusions of a recent study by Britt et al, (18), that, although there are some differences between the reported barriers to accessing mental and physical health care, there are more similarities.

\section{Independent links between barrier factors and accessing care}

All the barrier factors significantly increased the odds of not accessing care in both the mental and physical health conditions. Of note, the crude odds ratios of not seeking care for barriers related to self-treatment, identity, and resources were reasonably large, with some crude ORs above 4, indicating that the odds of not accessing formal care when needed in the scenarios was at least four times higher for those who reported these barriers compared to those who did not. This finding is both statistically and clinically significant, and these estimates are much higher than those published in other studies of military populations (e.g., Sudom et al, noted crude ORs below 1.6 for all types of barriers (21)). Also of note, aside from Staffing and workload resources and Intentions to self-treat, the barrier factors with the highest endorsement were not the most impactful. Together these findings suggest that perceived impact of barriers may not be as predictive of behaviour as previously thought. For example, barriers related to the discomfort accessing care at work were highly endorsed but were not the strongest predictors of avoiding accessing care in the scenarios. Our results suggest that although respondents perceived accessing care at their workplace as a key barrier, many respondents who endorsed this barrier still indicated they would access care in the scenarios.

\section{Association controlled for the demographic, military, and health variables}

Then, we modelled the association between the barrier factors and the health scenarios while controlling for the demographic, military, and health variables. Weak general intent to access care was consistently the strongest predictor of not accessing both physical and mental health care even when controlling for other barriers, demographic, military, and health variables. The findings appear to be in line with many studies that have reported that intention is a consistent predictor of health care providers' professional behaviour (27, 28).

The literature suggests that cognitive factors (such as beliefs about capabilities, beliefs about consequences, social influences, professional role, and identity), past behaviour, emotion, and to a lesser extent, environmental influences, and knowledge often influence a health care professional's intentions towards a variety of behaviours such as care seeking (27). In other words, the other barrier factors included in this study may be indirectly impacting care seeking through their association with intent to access care. Thus, interventions targeting barriers related to these domains may concurrently reduce barriers and improve intentions to access care which should subsequently improve access to care.

Interestingly, none of the barrier factors significantly increased the odds of not accessing physical health care in the adjusted models. However, Staffing and workload resources was a marginally significant predictor of the likelihood of not accessing care for back pain, but not pneumonia. It is important to note that though we have created distinct barrier factors, they are derived from theoretical domains that have conceptual overlap. As an example, barriers in the Organizational and social support factor relate to how the perceptions or actions of others influence whether an individual accesses care, which could also impact one's identity (CAF HCP identity factor). Though there were no issues with multicollinearity in the model (and no univariate correlations greater than .60), the conceptual overlap between the factors may be contributing to the lack of significant findings in the model. As discussed above, barriers may be indirectly influencing access to care through intent to access care. Even if the barrier factors were not significant in the adjusted model, they did have strong associations with physical care seeking when examined alone. Additionally, the adjusted models themselves were significant, suggesting that the barriers are playing a role.

Endorsing Staffing and workload resources significantly increased the odds of not accessing care across both mental health conditions. Intentions to self-treat also was a significant predictor in the adjusted mental health models (but not in the physical health models). This finding is in line with past research that has found higher estimates for the preference to self-treat in the mental health context compared to the physical health context (18). As mentioned above, the lack of significance in the adjusted model does not necessarily indicate that no other barriers are impactful. However, the findings do suggest that resources and intention to self-treat are strong barriers when considering whether to access mental health care. Studies have used behavioural change techniques such as mental rehearsal and goal setting/planning to address motivation constructs (29) and evidence suggests that providing information about the consequences of not accessing care could target attitudinal and emotional barriers related to the intent to self-treat $(29,30)$. However, we must remember that accessing care is not a single action. Behaviour often involves a complex sequence of actions over time (25) and the barriers may differ at each step. For example, a CAF health care provider may need to first recognise the need for formal care, deal with resource issues when scheduling a time to seek care, then face privacy concerns to attend care at their place of work. The impact of a barrier on a behaviour may be attenuated by one or more barriers acting at a different step in the chain (25). Just as the barriers encountered at each step differ, so 
might the processes required to change behaviour. Interventions that target barriers risk not improving access to care behaviour if other barriers in the sequence are not also addressed.

\section{Stigma}

Though much of the literature has focused on stigma as the top barrier to mental health care in military populations (20), more recent studies have noted the relative importance of barriers related to intentions (18), attitude towards care (21), and capabilities (such as resources, support and structural barriers (21)). Stigma related items were classified under the CAF HCP identity factor, (including items such as "I feel that others will discriminate against me if I access care" and "I feel embarrassed when I have to access care"). The unadjusted odds ratio for CAF HCP identity predicting not accessing care for mental health was relatively high. However, CAF HCP identity was not one of the most endorsed factors and was not a significant predictor of access to care in any of the adjusted models. This suggests that though stigma remains an important construct to consider, its influence on behaviour may be indirect or simply an indicator of motivation.

\section{Strengths and limitations}

Several sources of bias may have resulted from the study methods and design. Although we were able to impute missing data, we must note that less than half of the target population completed the survey. Therefore the results may not be generalizable to the entire CAF health care provider population. We expect that the experience of certain types of barriers may also be associated with non-participation. For example, those who experience resource issues, such as lack of time to seek care, likely also lack the time to complete a survey. Another limitation is that some of the barriers are specific to CAF HCPs (e.g., healthcare provider identity or accessing care at work), and may differ from those experienced by other military trades or civilian providers, particularly those who do not seek treatment where they are employed. However, the items could be modified (e.g., items removed or reworded) to better reflect barriers experienced by other populations. As with most research, all predictors and outcomes were self-report and thus subject to known biases (31, 32). Last, we were not able to measure actual care seeking behaviour. The literature suggests that subjective measures (i.e., self-report) are more effective at predicting a self-reported behaviour outcome than objective measures (27), thus participant's predicted behaviour in the hypothetical scenarios is likely not a perfect reflection of what they would do in that scenario $(32,33)$ and may inflate the proportion of variance explained in the models. Future studies should explore whether the results of this study are reproducible using measures of actual behaviour.

Despite the limitations, this is the first published example of a study that has quantified the impact of a variety of barriers to care developed using a theoretical framework. Unique to this study, we were able to demonstrate the relative impact of a breadth of theorybased barrier factors on accessing care across a variety of health contexts. The use of vignettes helps to define the context of the behaviour (27), allowing us to highlight key differences in behaviour between health conditions. Studies that are too narrowly focused on a single type of barrier or context may overlook important factors and miss opportunities to intervene. Additionally, the use of theory-based barrier factors provides a deeper understanding of access to care issues using established methods and behavioural constructs (16, 27, 34). This research will enable the development of context specific and evidence-based interventions to improve access to care by targeting psychosocial constructs (29) that, unlike demographics, are amenable to change.

\section{Conclusion}

Our findings suggest that intention to access care is the strongest predictor of care seeking. A lack of resources and intention to self-treat directly and negatively influence access to care. Additionally, other barriers may potentially be influencing access to care, indirectly through intent to access care. Given the findings, it appears that the best strategy moving forward is to target both intent to access care as well as barriers that may be impacting intent to access care. Using a multi-prong theoretical approach to barrier reduction provides the best opportunity for behavioural change and increasing access to care.

\section{Abbreviations}

AOR - Adjusted odds ratio

CAF - Canadian Armed Forces

FMI - Fraction of missing information

HCPs - Health care providers 
JNCM - Junior non-commission member

PTSD - Post-traumatic stress disorder

$\mathrm{RVI}$ - Relative increases in variance

SNCM - Senior non-commission member

SE - Standard error of the mean

crude OR - unadjusted odds ratio

\section{Declarations}

\section{Acknowledgements}

First and foremost, we would like to thank all those who participated in the study for their willingness to provide their perspectives and health information. Additionally, the support we received from the Health Services Group, unit leadership and administrative staff from across Canada was instrumental in developing, piloting, and launching this survey. Specifically we would like to thank Col Colleen Forestier, LCol Roger Tremblay, Dr. Sylvie Bourgeois and Dr. Cairina Frank for reviewing the health scenarios. Finally, the authors would like to acknowledge Dr. Jennifer Lee and Dr. Deniz Fikretoglu for their support in the development of this manuscript.

\section{Funding}

This research was funded by the Department of National Defence

\section{Availability of data and materials}

The data sets used and/or analysed during the current study are subject to the Access to Information Act and can be requested from the Government of Canada, through an access to information request online https://atip-aiprp.tbs-sct.gc.ca/ or by contacting the National Defence Access to Information and Privacy Coordinator at ATIP-AIPRP@forces.gc.ca.

Authors' information

J Born \& C Frank.

\section{Affiliations}

Director General Military Personnel Research and Analysis, Department of National Defence, Ottawa, Canada.

\section{Contributions}

JB developed the research program, analyzed and interpreted the survey data and was a major contributor in writing the manuscript. CF validated the barrier scale, managed the survey and contributed to the writing and editing of the manuscript. All authors read and approved the final manuscript.

\section{Corresponding author}

Correspondence to J. Born.

\section{Ethical Declarations}

\section{Consent for publication}

Not applicable

\section{Ethics approval and consent to participate}

This study was given ethical approval by the DGMPRA Social Science Research Review Board, in accordance with DAOD 5062-0 (35) and 5062-1 (36). The SSRRB approval \# is 1801/18F. The participants received written information about the study and gave written (electronic) informed consent before they participated in the survey. 


\section{Competing interests}

The authors declare that they have no competing interests. This manuscript presents the opinions of the authors and does not necessarily reflect the official position of the Department of National Defence or Canadian Armed Forces.

\section{References}

1. Adler AB, Bartone PT. International survey of military mental health professionals. Military Medicine. 1999;164(11):788-92.

2. Bernal D, Campos-Serna J, Tobias A, Vargas-Prada S, Benavides FG, Serra C. Work-related psychosocial risk factors and musculoskeletal disorders in hospital nurses and nursing aides: a systematic review and meta-analysis. International journal of nursing studies. 2015;52(2):635-48.

3. Shaukat N, Ali DM, Razzak J. Physical and mental health impacts of COVID-19 on healthcare workers: A scoping review. International Journal of Emergency Medicine. 2020;13(1):1-8.

4. Cieslak R, Anderson V, Bock J, Moore BA, Peterson AL, Benight CC. Secondary traumatic stress among mental health providers working with the military: Prevalence and its work-and exposure-related correlates. The Journal of nervous and mental disease.

2013;201(11):917.

5. Gibbons SW, Barnett SD, Hickling EJ. Family stress and posttraumatic stress: The impact of military operations on military health care providers. Archives of Psychiatric Nursing. 2012;26(4):e31-e9.

6. Milliken CS, Auchterlonie JL, Hoge CW. Longitudinal assessment of mental health problems among active and reserve component soldiers returning from the Iraq war. Jama. 2007;298(18):2141-8.

7. Cedfeldt AS, Bower EA, Grady-Weliky TA, Flores C, Girard DE, Choi D. A comparison between physicians and demographically similar peers in accessing personal health care. Academic Medicine. 2012;87(3):327-31.

8. Hall LH, Johnson J, Watt I, Tsipa A, O'Connor DB. Healthcare staff wellbeing, burnout, and patient safety: a systematic review. PloS one. 2016;11(7):e0159015.

9. Leape LL, Fromson JA. Problem doctors: is there a system-level solution? Annals of Internal Medicine. 2006;144(2):107-15.

10. Parsons IT. The health of the Role 1 doctor. Journal of the Royal Army Medical Corps. 2015;161(4):300-3.

11. Davidson SK, Schattner PL. Doctors' health-seeking behaviour: a questionnaire survey. Medical Journal of Australia. 2003;179(6):3025.

12. Steffen M, Hagen P, Benkhadra K, Molella R, Newcomb R, Murad M. A survey of physicians' perceptions of their health care needs. Occupational Medicine. 2015;65(1):49-53.

13. Hoge CW, Castro CA, Messer SC, McGurk D, Cotting DI, Koffman RL. Combat duty in Iraq and Afghanistan, mental health problems, and barriers to care. N Engl J Med. 2004;351(1):13-22.

14. Kay M, Mitchell G, Clavarino A, Doust J. Doctors as patients: a systematic review of doctors' health access and the barriers they experience. Br J Gen Pract. 2008;58(552):501-8.

15. Cochrane LJ, Olson CA, Murray S, Dupuis M, Tooman T, Hayes S. Gaps between knowing and doing: understanding and assessing the barriers to optimal health care. Journal of continuing education in the health professions. 2007;27(2):94-102.

16. Michie S, Johnston M, Abraham C, Lawton R, Parker D, Walker A. Making psychological theory useful for implementing evidence based practice: a consensus approach. BMJ Quality \& Safety. 2005;14(1):26-33.

17. Frank C, Born, J. Development and validation of the Barriers to Care Scale: Assessing access to care among Canadian Armed Forces health care providers. 2021.

18. Britt TW, Sipos ML, Klinefelter Z, Adler AB. Determinants of mental and physical health treatment-seeking among military personnel. The British Journal of Psychiatry. 2020;217(2):420-6.

19. Kay M, Mitchell G, Clavarino A, Doust J. Doctors as patients: a systematic review of doctors' health access and the barriers they experience. British Journal of General Practice. 2008;58(552):501-8.

20. Gould M, Adler A, Zamorski M, Castro C, Hanily N, Steele N, et al. Do stigma and other perceived barriers to mental health care differ across Armed Forces? J R Soc Med.103(4):148-56.

21. Sudom K, Zamorski M, Garber B. Stigma and barriers to mental health care in deployed Canadian forces personnel. Military Psychology. 2012;24(4):414-31.

22. Born J, Frank, C., Richer, I. C4C Access to Health Care: Results of the Barriers to Care Survey of Health Care Providers in the Canadian Armed Forces Ottawa, ON: Defence Research and Development Canada, Government of Canada; 2021. 
23. StataCorp. mi impute - Imputing missing values. 2013. In: Stata 13 Base Reference Manual [Internet]. Colledge Station, TX: Stata Press.

24. Schafer JL. Imputation of missing covariates under a multivariate linear mixed model. Tech; 1997.

25. StataCorp. mi estimate using - Estimation using previously saved estimation results. 2013. In: Stata 13 Base Reference Manual [Internet]. College Station, TX: Stata Press. Available from:

https://www.stata.com/manuals13/mimiestimateusing.pdf\#mimiestimateusing.

26. Stata Statistical Software:. College Station, TX: StataCorp LP; 2015.

27. Godin G, Bélanger-Gravel A, Eccles M, Grimshaw J. Healthcare professionals' intentions and behaviours: A systematic review of studies based on social cognitive theories. Implementation science. 2008;3(1):1-12.

28. Michie S, West R, Sheals K, Godinho CA. Evaluating the effectiveness of behavior change techniques in health-related behavior: a scoping review of methods used. Translational Behavioral Medicine. 2018;8(2):212-24.

29. Carey RN, Connell LE, Johnston M, Rothman AJ, De Bruin M, Kelly MP, et al. Behavior change techniques and their mechanisms of action: a synthesis of links described in published intervention literature. Annals of Behavioral Medicine. 2019;53(8):693-707.

30. Michie S, Wood CE, Johnston M, Abraham C, Francis J, Hardeman W. Behaviour change techniques: the development and evaluation of a taxonomic method for reporting and describing behaviour change interventions (a suite of five studies involving consensus methods, randomised controlled trials and analysis of qualitative data). Health technology assessment. 2015;19(99).

31. Van de Mortel TF. Faking it: social desirability response bias in self-report research. Australian Journal of Advanced Nursing, The. 2008;25(4):40.

32. Donaldson SI, Grant-Vallone EJ. Understanding self-report bias in organizational behavior research. Journal of business and Psychology. 2002;17(2):245-60.

33. Boase J, Ling R. Measuring mobile phone use: Self-report versus log data. Journal of Computer-Mediated Communication. 2013;18(4):508-19.

34. Michie S, Van Stralen MM, West R. The behaviour change wheel: a new method for characterising and designing behaviour change interventions. Implementation science. 2011;6(1):42.

35. Chief of Military Personnel. DAOD 5062-0, Social Science Research. 2014. Retrived from https://www.canada.ca/en/departmentnational-defence/corporate/policies-standards/defence-administrative-orders-directives/5000-series/5062/5062-0-social-scienceresearch.html

36. Chief of Military Personnel. DAOD 5062-1, Conduct of Social Science Research. 2014. Retrived from https://www.canada.ca/en/department-national-defence/corporate/policies-standards/defence-administrative-orders-directives/5000series/5062/5062-1-conduct-of-social-science-research.html

\section{Figures}




\section{Barrier Factor}

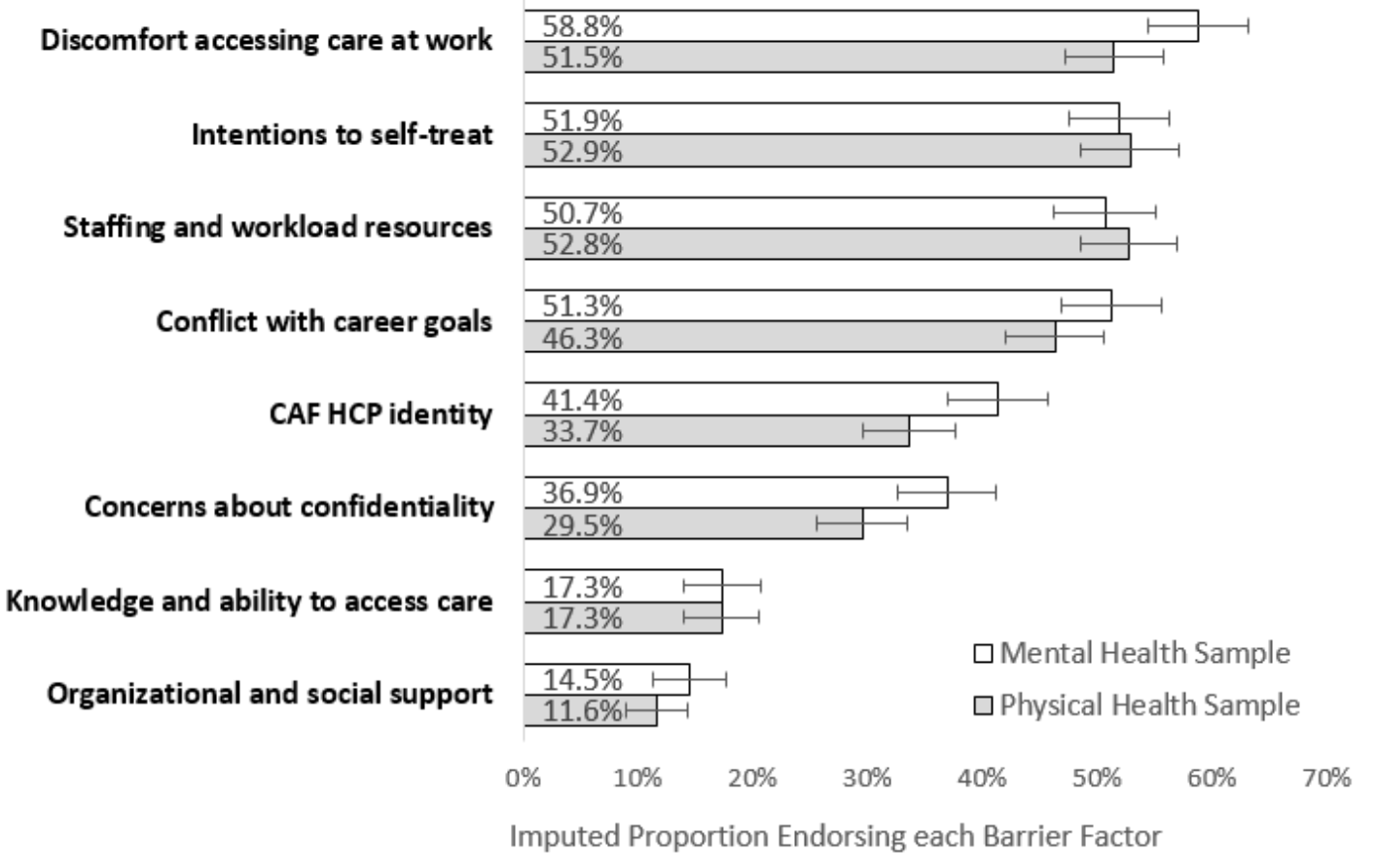

Figure 1

Imputed proportion of respondents who endorsed barrier factors in each sample

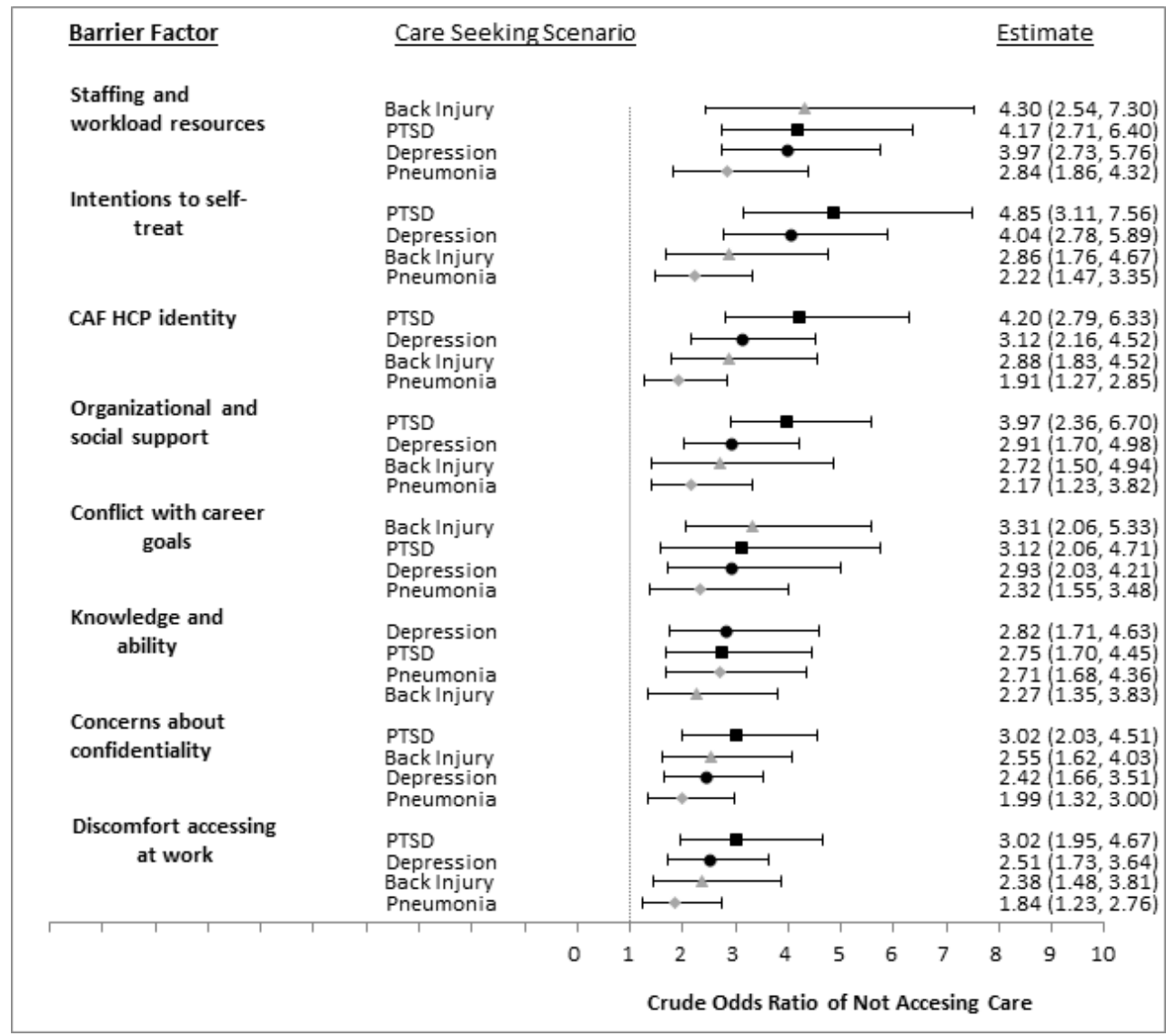

\section{Figure 2}


Imputed odds of not accessing care, given endorsement of a barrier factor

\section{Supplementary Files}

This is a list of supplementary files associated with this preprint. Click to download.

- Additionalfile1.docx

- Additionalfile2.docx 